\title{
Aberrant phenotypes of transgenic mice expressing dimeric human erythropoietin
}

\author{
Seong-Jo Yun', Purevjargal Naidansuren ${ }^{1}$, Bo-Woong Sim¹', Jong-Ju Park', Cha-Won Park', Tseeleema Nanjidsuren², \\ Myung-Hwa Kang ${ }^{2}$, Sue-Yun Hwang ${ }^{1}$, Jong-Taek Yoon ${ }^{1}$ and Kwan-Sik Min ${ }^{1 *}$
}

\begin{abstract}
Background: Dimeric human erythropoietin (dHuEPO) peptides are reported to exhibit significantly higher biological activity than the monomeric form of recombinant EPO. The objective of this study was to produce transgenic (tg) mice expressing dHuEPO and to investigate the characteristics of these mice.

Methods: A dHuEPO-expressing vector under the control of the goat beta-casein promoter, which produced a dimer of human EPO molecules linked by a 2-amino acid peptide linker (Asp-lle), was constructed and injected into 1-cell fertilized embryos by microinjection. Mice were screened using genomic DNA samples obtained from tail biopsies. Blood samples were obtained by heart puncture using heparinized tubes, and hematologic parameters were assessed. Using the microarray analysis tool, we analyzed differences in gene expression in the spleens of tg and control mice.
\end{abstract}

Results: A high rate of spontaneous abortion or death of the offspring was observed in the recipients of dHuEPO embryos. We obtained 3 founder lines (\#4, \#11, and \#47) of tg mice expressing the dHuEPO gene. However, only one founder line showed stable germline integration and transmission, subsequently establishing the only transgenic line (\#11). We obtained 2 F1 mice and 3 F2 mice from line \#11. The dHuEPO protein could not be obtained because of repeated spontaneous abortions in the tg mice. Tg mice exhibited symptoms such as short lifespan and abnormal blood composition. The red blood cell count, white blood cell count, and hematocrit levels in the tg mice were remarkably higher than those in the control mice. The spleens of the tg mice (F1 and F2 females) were 11- and -21-fold larger than those of the control mice. Microarray analysis revealed 2,672 spleenderived candidate genes; more genes were downregulated than upregulated (849/764). Reverse transcriptasepolymerase chain reaction (RT-PCR) and quantitative real-time PCR (qRT-PCR) were used for validating the results of the microarray analysis of mRNA expression.

Conclusions: In conclusion, dHuEPO tg mice caused excessive erythrocytosis that led to abnormal blood composition, short lifespan, and abnormal splenomegaly. Further, we identified 2,672 genes associated with splenomegaly by microarray analysis. These results could be useful in the development of dHuEPO-producing tg animals.

\section{Background}

Erythropoietin (EPO), a 30.4-kDa glycoprotein hormone secreted mainly by peritubular cells of the adult kidney, is the major factor regulating red blood cell $(\mathrm{RBC})$ production [1]. Recombinant human EPO (rhEPO) has been approved for the treatment of anemia resulting from chronic renal failure, cancer chemotherapy, AIDS,

\footnotetext{
* Correspondence: ksmin@hknu.ac.kr

'Animal Biotechnology, Graduate School of Bio \& Information Technology, Institute of Genetic Engineering, Hankyong National University, Ansung 456749, Korea

Full list of author information is available at the end of the article
}

etc. [2-4]. Administration of rhEPO as a potential therapeutic agent can reduce the necessity for blood transfusions and improve the patients' quality of life. Although rhEPO may be beneficial for the patients, the price of such a treatment prevents its use as a long-term intravenous treatment. Therefore, various strategies have been used to stimulate erythropoiesis. Many approaches to extend the half-life of EPO through genetic changes or chemical modification of native EPO have been considered in detail $[5,6]$. All these strategies have shown some effect on extending the half-life and enhancing the activities of rhEPO. Particularly, dimerization of 2

\section{() Biomed Central}


rhEPO peptides can significantly enhance the biological activity of the hormone; this is because the dimer has 2 high-affinity binding sites, resulting in better binding to the EPO receptor than is observed with the monomeric form of recombinant rhEPO [7-9]. Similarly, the longer half-life of novel erythropoietin stimulating protein (NESP), which was created by the introduction of 2 extra $\mathrm{N}$-linked carbohydrate addition sites into the primary sequence of EPO, is likely to afford it a clinical advantage over rhEPO by allowing less frequent dosing in patients treated for anemia [10]. An EPO chimeric protein, constructed by fusing the carboxyl-terminal peptide of a human chorionic gonadotropin- $\beta$ subunit bearing 4 O-linked oligosaccharide recognition sites with the coding sequence of human EPO cDNA, did not show altered secretion, receptor binding affinity, or in vitro bioactivity, but had significantly enhanced in vivo potency and half-life [11]. We also studied the production of rhEPO in mammalian cells and observed that hyperglycosylated rhEPO (HGEPO) and dHuEPO have higher erythropoietic activity than wild-type rhEPO, both in vitro and in vivo [12-14].

Transgenic (tg) animals are an attractive alternative to cell cultures for high-level, low-cost production of proteins. The mammary gland is the most reasonable organ for the production of recombinant proteins from transgenic organisms $[15,16]$ and is suitable for synthesis of large amounts of protein that can be easily collected without causing harm to the animal [17]. Attempts have been made to obtain transgenic mice showing enhanced expression of the monomeric form of EPO [18-20]. We have also produced transgenic pigs expressing hEPO protein in the mammary gland, and showed that the purified hEPO had erythropoietic activity [21]. However, there has been no report on the generation of transgenic mice expressing the $\mathrm{dHuEPO}$ form. In the present study, we produced tg mice expressing dHuEPO, which was constructed by linking 2 human EPO molecules using a 2 -amino acid peptide linker. dHuEPO tg mice developed excessive erythrocytosis that led to short lifespan, debility, and abnormal splenomegaly. Further, by microarray analysis, we have identified 2,672 genes associated with splenomegaly.

\section{Methods}

\section{Construction of the dHuEPO gene}

The N-terminal EPO domain of the human EPO dimerencoding construct was amplified by polymerase chain reaction (PCR) with a plasmid containing the human EPO cDNA [12] using the primers EPO 1 (5'-TGG TCG ACA CCA TGG GGG TGC ACG AAT GTC CT3'), which contains the SalI site at the 5' end, and EPO 2 (5'-AGG ATA TCT CTG TCC CCT GTC CTG CAG
GC-3'), which contains the Asp-Ile ligation site that was used to ligate 2 EPO molecules. With the exception of the stop codon, the complete EPO open-reading frame is present in this domain. The C-terminal EPO domain was constructed using the primers EPO 3 (5'-ATG ATA TCG CCC CAC CAC GCC TCA TC-3'), which contains the Asp-Ile ligation site and in which the signal sequence was removed, and EPO 4 (5'-TAC TCG AGT TCA TCT GTC CCC TGT CCT GCA-3'), which contains the SalI site at the 3' end. This domain also contains the complete open-reading frame but not the signal sequence. The plasmid was constructed by ligation of the 6 nucleotide residues encoding the peptide linker fragment (Asp and Ile). The dimeric EPO molecule was constructed by the overlapping PCR method as previously reported [22]. The first PCR was performed using primers EPO 1-2 and 3-4. The resulting fragments were digested by $\mathrm{XhoI} / \mathrm{SalI}$ and ligated into the unique XhoI site of the expression vector $\mathrm{pBC} 1$ under the control of the goat $\beta$-casein promoter (designated as $\mathrm{pBC} 1$ $\mathrm{dHuEPO}$ ). The direction of the ligated fragment was confirmed by restriction mapping using XhoI and SalI. The sequence of the entire dHuEPO cDNA was verified by automated DNA sequencing performed as previously reported [22].

\section{Production and screening of transgenic mice}

$\mathrm{Tg}$ mice were obtained by pronuclear microinjection of the $\mathrm{dHuEPO} \mathrm{cDNA}$ driven by the goat $\beta$-casein promoter; microinjection was performed as previously described [23]. C57BL/6 N mice were used for the experiment. All mice were raised and maintained in the facilities of Macrogen Laboratories (Seoul, Korea). Potential tg mice were screened using genomic DNA samples obtained from tail biopsies. The PCR primers were as follows: EPO-1 F, 5'-CCC AGA ATC TAA GCG ATA TCT GGC-3' and EPO-1R, 5'-GCC CAG GAC TGG GAG GCC CAG AGG-3'. PCR was performed over 35 cycles $\left(1 \mathrm{~min}\right.$ at $94^{\circ} \mathrm{C}, 1 \mathrm{~min}$ at $56^{\circ} \mathrm{C}$, and $1 \mathrm{~min}$ at $72^{\circ} \mathrm{C}$ ). The predicted PCR product was $607 \mathrm{bp}$ in length. The tg mice were bred by mating heterozygous male/female mice with wild-type females/ males. The experiments were conducted according to the Guidelines for the Care and Use of Laboratory Animals, Hankyong National University.

\section{Blood analysis}

Blood samples of the control and tg mice were obtained by heart puncture, collected in heparinized tubes, and placed on ice immediately. We examined $100 \mu \mathrm{L}$ of blood on a HEMAVET 950 Automatic Cell Counter. Hematologic parameters examined included white blood cell (WBC) count, RBC count, and hematocrit (HCT). 


\section{Reverse transcriptase-polymerase chain reaction (RT-PCR) analysis}

Isolation of total RNA of frozen hearts, kidneys, livers, lungs, and spleens was performed using the TRIzol method (Invitrogen, Carlsbad, CA) according to the manufacturer's specifications. The final RNA sample was treated with DNase to prevent DNA contamination. For RT-PCR analysis, the reverse transcription reaction was performed with $8 \mu \mathrm{g}$ of total RNA using SuperScript II Reverse Transcriptase and oligo(dT) primers according to the manufacturer's protocols. Two microliters of cDNA were used in each PCR reaction. The dHuEPO gene was detected using a forward primer (5'ATG AGA ATA TCA CTG TCC CA-3') and a reverse primer (5'-GTG TCA GCA GTG ATT GTT CG-3'), which yielded 304- and 808-bp DNA fragments, respectively. The PCR conditions were 30 cycles of $30 \mathrm{~s}$ at $94^{\circ}$ $\mathrm{C}, 30 \mathrm{~s}$ at $56^{\circ} \mathrm{C}$, and $30 \mathrm{~s}$ at $72^{\circ} \mathrm{C}$. Glyceraldehyde 3phosphate dehydrogenase (GAPDH) was used for normalization of the $\mathrm{dHuEPO}$ expression, and the following GAPDH primer sequences were used for the normalization procedure: forward, 5'-ACC ACA GTC CAT GCC ATC AC-3' and reverse, 5'-TCC ACC ACC CTG TTG CTG TA-3'. The expected PCR fragment had a length of $452 \mathrm{bp}$. The PCR conditions were 26 cycles of $10 \mathrm{~s}$ at $98^{\circ} \mathrm{C}, 2 \mathrm{~s}$ at $55^{\circ} \mathrm{C}$, and $20 \mathrm{~s}$ at $72^{\circ} \mathrm{C}$.

\section{Splenectomy and histological analysis}

Necropsy of the transgenic mice showed severe splenomegaly. The spleen was quickly removed for RNA preparation. Samples were kept in liquid nitrogen and stored individually at $-80^{\circ} \mathrm{C}$. The weight of the spleens of wild-type (wt) and tg mice was determined. Mice were necropsied, and the freshly dissected tissues from spleens were fixed in $10 \%$ formalin solution. Fixed specimens were embedded in paraffin and then cut into 4$\mu \mathrm{m}$-thick sections. The sections were stained with hematoxylin and eosin ( $\mathrm{H} \& \mathrm{E})$ according to standard protocols.

\section{Microarray analysis}

Total RNA was extracted using the TRIzol reagent and purified using RNeasy columns (Qiagen, Valencia, CA) according to the manufacturer's protocol. After DNase digestion and clean-up procedures, the RNA samples were quantified, aliquoted, and stored at $-80^{\circ} \mathrm{C}$ until use. For quality control, RNA purity and integrity were evaluated by performing denaturing gel electrophoresis and obtaining the optical density (OD) 260/280 ratio; these analyses were performed on an Agilent 2100 Bioanalyzer (Agilent Technologies, Palo Alto, CA).

\section{Labeling and purification}

Total RNA was amplified and purified using the Ambion Illumina RNA amplification kit (Ambion,
Austin, TX) to yield biotinylated cRNA according to the manufacturer's instructions. Briefly, $550 \mathrm{ng}$ total RNA was reverse-transcribed to cDNA using a T7 oligo(dT) primer. Second-strand cDNA was synthesized, in vitro transcribed, and labeled with biotin-NTP. After purification, the cRNA was quantified using the ND-1000 Spectrophotometer (NanoDrop, Wilmington, DE).

\section{Hybridization and data export}

We hybridized $750 \mathrm{ng}$ of labeled cRNA samples to each Mouse- 8 Expression Bead array for $16-18$ h at $58^{\circ} \mathrm{C}$ according to the manufacturer's instructions (Illumina, Inc., San Diego, CA). The detection of the array signals was performed using Amersham Fluorolink streptavidinCy3 (GE Healthcare Bio-Sciences, Little Chalfont, UK) in accordance with the bead array manual. Arrays were scanned with an Illumina Bead Array Reader confocal scanner according to the manufacturer's instructions. Array data were exported and analysis was performed using Illumina BeadStudio v3.1.3 (Gene Expression Module v3.3.8).

\section{Raw data preparation and statistical analysis}

The quality of hybridization and overall chip performance was monitored by visual inspection of both internal quality controls and scanned raw data. The raw data were extracted using the software provided by the manufacturer (Illumina BeadStudio v3.1.3; Gene Expression Module v3.3.8). The array data were filtered by a detection $p$-value $<0.05$ (similar to signal-to-noise ratio) in at least $50 \%$ of the samples (we applied a filtering criterion for data analysis; a higher signal value was required to obtain a detection $p$-value $<0.05)$. Selected gene signal values were transformed using a logarithm and normalized by the quantile method. The comparative analysis between the test and control groups was performed using the $t$ test (adjusted Benjamini-Hochberg false discovery rate [FDR], 5\% controlled) and fold-change values. Hierarchical cluster analysis was performed using complete linkage and Euclidean distance as measures of similarity. All data analyses and visualization of differentially expressed genes were conducted using ArrayAssist $^{\circledR}$ (Stratagene, La Jolla, CA) and R statistical language v. 2.4.0. Ontology-based analysis was performed using the Panther database [24].

\section{Quantitative real-time PCR (qRT-PCR)}

To validate the microarray data, 20 genes from different categories, including platelet factor $4(P f 4)$; Fc receptor, IgG, low affinity IV (Fcgr4); proteoglycan 2, bone marrow (Prg2); haptoglobin $(H p)$; elastase, neutrophil expressed (Elane); tribbles homolog 3 (Trib3); S100 calcium binding protein A9 (calgranulin B) (S100a9); pleckstrin 2 (Plek2); formyl peptide receptor 2 (Fpr2); histocompatibility 2, class II, locus Mb2 (H2-DMb2); chemokine ( $\mathrm{C}-\mathrm{X}-\mathrm{C}$ motif) receptor 5 (Cxcr5); Fc 
receptor-like A (Fcrla); complement factor D (adipsin) $(C f d)$; C-type lectin domain family 4 , member $\mathrm{g}$ (Clec4g); chemokine (C-C motif) receptor 6 (Ccr6); CD79B antigen $(C d 79 b)$; CD40 antigen $(C d 40)$; CD6 antigen (Cd6); and inositol 1, 4, 5-triphosphate receptor 2 (Itpr2), were chosen for qRT-PCR analyses. Primer sequences and primer annealing temperatures are outlined in Table 1. Primers were designed using Primer3 software [25]. One microgram of total RNA was reverse transcribed to cDNA using oligo $(\mathrm{dT})$ primers with the first-strand cDNA synthesis kit for RT-PCR (Invitrogen) according to the manufacturer's instructions. qRT-PCR was performed in a Rotor-Gene ${ }^{\mathrm{TM}} 6000$ (Corbett Life Science, Mortlake, Australia). The reaction mixture consisted of $100 \mathrm{ng}$ DNA, $4 \mathrm{nM}$ of each primer, and $10 \times$ qPCR Mastermix Plus (Toyobo, Osaka, Japan) in a total volume of $20 \mu \mathrm{L}$. A negative control containing all reagents minus DNA was included in each run. All reactions were performed with an initial denaturation for 10 min at $95^{\circ} \mathrm{C}$ followed by 40 cycles of $95^{\circ} \mathrm{C}$ for $10 \mathrm{~s}$, the respective annealing temperature (Table 1 ) for $15 \mathrm{~s}$, and $72^{\circ} \mathrm{C}$ for $20 \mathrm{~s}$. The housekeeping gene $\beta$-actin was run in parallel. The threshold cycle number and reaction efficiency were determined using the Rotor-Gene 6000 series software version 6.1.93; the $2^{-{ }^{-D D C}} \mathrm{~T}$ method was used for relative quantitation. Absence of primers and the presence of the correct amplicon size for the specific
SYBR green assays were verified by melting-curve analysis.

\section{Results}

\section{Production of dHuEPO tg mice}

A total of 1,018 1-cell stage embryos were transferred to 52 recipient mice on day 1 of the estrous cycle (Table 2). Spontaneous abortion occurred in 23 recipients during mid-to-late pregnancy. Twenty-nine recipients (56\%) successfully farrowed after embryo transfer. Thirty mice died soon after birth. The mortality rate of the tg mice was $39 \%$, about 8 -fold higher than that of the control wt mice. Forty-seven live mice were screened. Three tg mice were identified by transgene-specific PCR. Three positive transgenic founder lines, i.e., \#3, \#11, and \#47, were obtained. One of these founders was female (\#3) and the other 2 were male $(\# 11, \# 47)$. All these founders produced offspring. PCR analysis of tail DNA samples revealed that only 1 (\#11) of the 3 lines was positive. Two offspring (F1) (1 male, 1 female) of this founder (\#11) were positive for the $d H u E P O$ gene. Five mice were born from the F1 male, of which 3 (F2; 2 male, 1 female) were positive for the $d H u E P O$ gene. The tg males (line \#11), including F1 and F2 males, had a short life span. The average lifespan of male mice was 71-72 days. The remaining 2 female mice (F1, F2) developed a moribund condition. Moreover, the F1 and

Table 1 The primer sets for genes used in qRT-PCR

\begin{tabular}{|c|c|c|c|c|c|c|}
\hline & $\begin{array}{c}\text { NCBI } \\
\text { ACCESSION } \\
\text { NUMBER } \\
\end{array}$ & Forward & $\mathrm{Tm}$ & Reverse & $\mathrm{Tm}$ & $\begin{array}{l}\text { size } \\
\text { (bp) }\end{array}$ \\
\hline \multirow[t]{5}{*}{ I } & NM_019932 & CCGAAGAAAGCGATGGAGAT & 57.3 & TTCAGGGTGGCTATGAGCTG & 59.3 & 139 \\
\hline & NM_144559 & CCGTGGCATCAAATCACATT & 59.4 & CCTGAGGTTCCTTGCTCCAT & 58.9 & 145 \\
\hline & NM_008920 & CTTGCCTAGGGATGCAGAGA & 59.4 & ATCCTGACCTGAGACAGCTC & 59.4 & 144 \\
\hline & NM_017370 & GTGCCCGAGAAGAAAAACTTG & 57.9 & AGGTGTCCTCCTCCATGTCA & 59.4 & 154 \\
\hline & NM_015779 & GAGGCTGTGGATCTGGATTG & 59.4 & TCCTAGTTGGTCCTGCCCT & 58.8 & 139 \\
\hline \multirow[t]{5}{*}{ II } & NM_144554 & GGAGAACCTGGAAGATGCCT & 59.4 & GATCTTGCCAAAGAGCAGGA & 57.3 & 142 \\
\hline & NM_175093 & ACGACTCTGAGCCAGTCCT & 58.8 & CCACAAGTCGCTCTGAAGGT & 59.4 & 132 \\
\hline & NM_009114 & GACACCCTGAGCAAGAAGGA & 59.4 & AGCTCAGCTGATTGTCCTGG & 59.4 & 139 \\
\hline & NM_013738 & AGGGGCACAAGAGGAAAAAC & 57.3 & ACACAAGGGAACCACGAAGA & 57.3 & 135 \\
\hline & NM_008039 & GCCAGGACTITCGTGAGAGA & 59.4 & CTTCATGGGGCCTTTAACTCA & 57.9 & 142 \\
\hline \multirow[t]{5}{*}{ III } & NM_010388 & TGGCTITGTGGCTCATGTGG & 59.4 & CACCCCAAATTCACAGGGGA & 59.4 & 148 \\
\hline & NM_007551 & AACCGAGACCTTCCTGTTCC & 59.1 & TGTGCAGAGCGATCACAGTT & 59 & 134 \\
\hline & NM_145141 & GCAACCCAGATGTTACTGGC & 59.1 & CAGCTTCACTGGATTGGGTC & 59.2 & 145 \\
\hline & NM_013459 & ATCATGAACCGGACAACCTG & 57.3 & AACCACACCTTCGACTGCAT & 57.3 & 150 \\
\hline & NM_029465 & AAGCGCCAGAACAGCTCCT & 58.8 & ATCACCAGATGGGCACCCT & 58.8 & 139 \\
\hline \multirow[t]{5}{*}{ IV } & NM_009835 & GCTTTCCTGCATTGCTGCCT & 59.4 & TAAACCCGGGCACAGAGGAA & 59.4 & 143 \\
\hline & NM_008339 & ACAAGGATGACGGCAAGGC & 58.8 & ATTCCTGGCCTGGATGCTC & 58.8 & 144 \\
\hline & NM_170702 & ACAGCGGTCCATCTAGGGCA & 61.4 & CATGGGTGGCATTGGGTCTT & 59.4 & 140 \\
\hline & NM_009852 & CAACTTGGAACTGGCTGGC & 58.8 & AGGGGGTCCTGGACATTCA & 58.8 & 148 \\
\hline & NM_019923 & TGCCGTAATCAACACCAGCG & 59.4 & TCTGCAGGAAGGTGTGGGCT & 61.4 & 136 \\
\hline V & $\beta$-actin & AGAGGGAAATCGTGCGTGAC & 59.3 & CAATAGTGATGACCTGGCCGT & 59.8 & 138 \\
\hline
\end{tabular}


Table 2 Embryo transfer and pregnancy rates of microinjected embryos

\begin{tabular}{cccc}
\hline $\begin{array}{c}\text { No. of 1-cell stage } \\
\text { Transferred }\end{array}$ & $\begin{array}{c}\text { No. of recipients farrowed/ } \\
\text { no. of recipients } \\
(\%)\end{array}$ & $\begin{array}{c}\text { No. of screened live offspring } \\
(\%)\end{array}$ & $\begin{array}{c}\text { No. of founders } \\
\text { (positive) } \\
\text { (\%) }\end{array}$ \\
\hline 1018 & $29 / 52$ & 47 & 3 \\
& $(56)$ & $(4.6)$ & $(6.4)$ \\
\hline
\end{tabular}

F2 female mice consistently aborted when they became pregnant. We performed autopsies on these 2 mice. Thus, we produced a total of 5 mice carrying the dHuEPO gene from founder \#11. F1 transmission rate from founder was $100 \%$. F2 transmission rate from F1 male was $60 \%(3 / 5)$.

\section{Blood composition of dHuEPO tg mice}

Mouse blood was collected by heart puncture. Blood analysis revealed that the $\mathrm{RBC}$ counts, WBC counts, and $\mathrm{HCT}$ values in the $\mathrm{dHuEPO} \mathrm{tg}$ mice were remarkably higher than those in the wt mice (Figure 1). The total WBC count was higher in the blood of $\operatorname{tg}$ mice (wt, 1.93 $\pm 0.08 \times 10^{3} / \mu \mathrm{L}$ vs. $\operatorname{tg} \mathrm{F} 1,13.43 \pm 0.97 \times 10^{3} / \mu \mathrm{L}$ and $\operatorname{tg}$ F2, $\left.10.77 \pm 0.21 \times 10^{3} / \mu \mathrm{L}\right)$. Similarly, the $\mathrm{RBC}$ count was higher in tg than in wt mice (wt, $9.43 \pm 1.03 \times 10^{6}$ / $\mu \mathrm{L}$ vs. tg F1, $17.97 \pm 0.03 \times 10^{6} / \mu \mathrm{L}$ and $\operatorname{tg} \mathrm{F} 2,13.57 \pm$ $\left.0.21 \times 10^{6} / \mu \mathrm{L}\right)$. Notably, we also found that the HCT value was significantly higher in tg mice than in wt mice (wt, $47.75 \pm 3.46 \%$ vs. $t g$ F1, $74.9 \pm 0.14 \%$ and $\operatorname{tg}$ F2, $63.45 \pm 0.92 \%)$.

\section{Expression of dHuEPO mRNA in tg mice}

We examined $\mathrm{dHuEPO}$ mRNA expression in various organs, and detected it using RT-PCR in the heart, kidney, liver, lung, and spleen (Figure 2). The 304- and 808-bp PCR amplicons were visualized on an agarose gel. The obtained PCR bands matched the predicted sizes. The expected PCR band was detected in most of the tissues examined indicating that tg mice expressed the $d H u E P O$ gene in several tissues. We did not detect any PCR band in the wt mice.
Tg mice showed distinct splenomegaly and an increased red pulp area

The distinct differences in the spleens of $\operatorname{tg}$ mice are shown in Figure 3. Tg mice exhibited severe splenomegaly. The wet weights of spleens from the F1 and F2 tg mice were 21 - and 11-fold higher than those of the spleens from wt mice (Figure 3A). When take the spleen, F1 female was 157 days in age and F2 female was 72 days in age. Thus, the spleen weight is difference between two mice. We observed H\&E-stained sections of spleens of F1 tg, F2 tg, and wt mice (Figure 3B). The spleens of F1 tg and F2 tg mice were easily distinguishable from spleens of the wt mice. The tg spleens showed a greater red pulp area than did wt spleens.

\section{Microarray image and data analysis}

Using the microarray analysis tool, we assessed statistically significant variations in the expression levels of the 2,672 candidate genes (Figure 4A). In comparison with the expression in the wt control mice, 764 genes were upregulated and 849 were downregulated in spleens of F1 tg mice, 1,155 genes were upregulated and 1,164 were downregulated in F2 tg mice; and 20 genes were upregulated and 243 were downregulated in both F1 tg and F2 tg mice. Figure $4 \mathrm{~B}$ shows the heat map (displaying differential expression levels) and hierarchical clustering of the chosen genes. The horizontal rows of the heat map represent genes, whereas the columns represent samples. Each pixel represents the expression of 1 gene in 1 experiment. Red represents upregulation, and green represents downregulation of gene expression, relative to wt levels. A greater portion of the heat map is green.
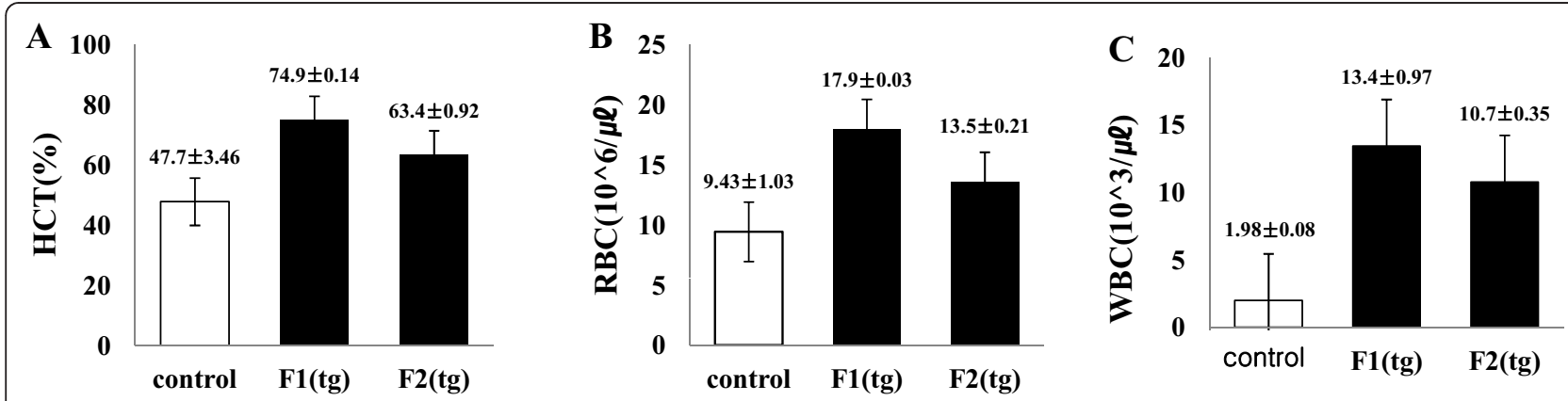

Figure 1 Blood cell counts of dHuEPO transgenic mice. Hematological parameters showed that tg mice had markedly increased RBC, WBC, and HCT values. All data are mean \pm SD. A: HCT (\%); B: RBC (× 10\% $/ \mu \mathrm{L}) ; \mathrm{C}: \mathrm{WBC}\left(\times 10^{3} / \mu \mathrm{L}\right)$. HCT: hematocrit; RBC: red blood cell; WBC: white blood cell; F1 (tg): F1 female mice produced from founder \#11; F2 (tg): F2 female mice produced from F1 founder male. 


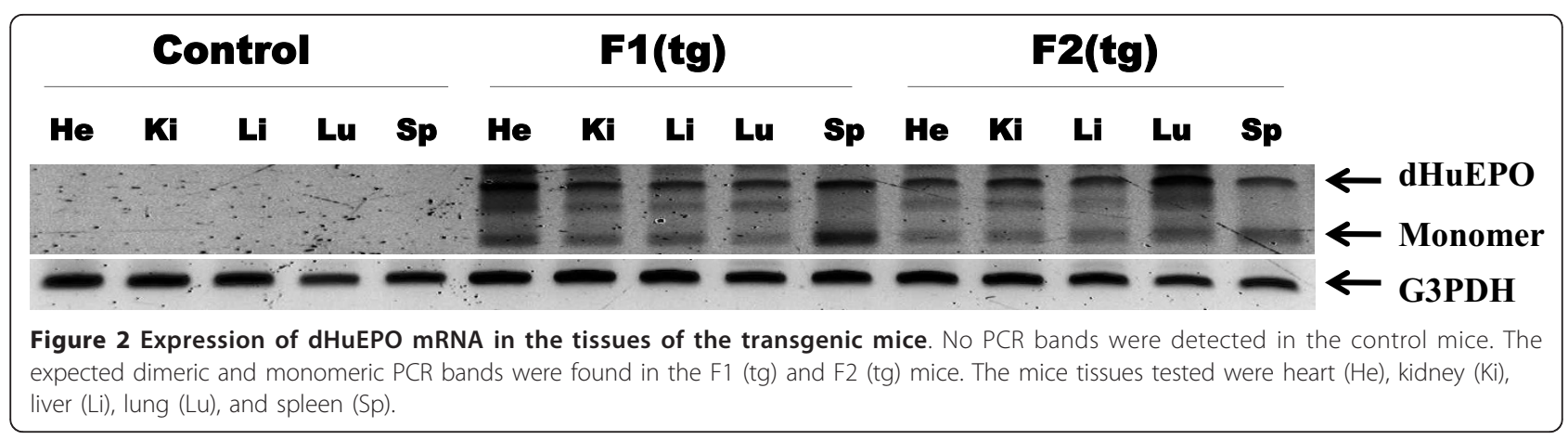

Biological network classification of splenomegalyassociated genes

We used the Panther database to assign gene ontology (GO) categories to the 2,672 genes showing significant transcriptional differences between wt and tg mice. The categorization of splenomegaly-associated genes according to the molecular function and biological process is shown in Figure 5. Categorization based on biological

A

Control

$\mathrm{F} 1(\mathrm{tg})$

F2 ( $\operatorname{tg})$
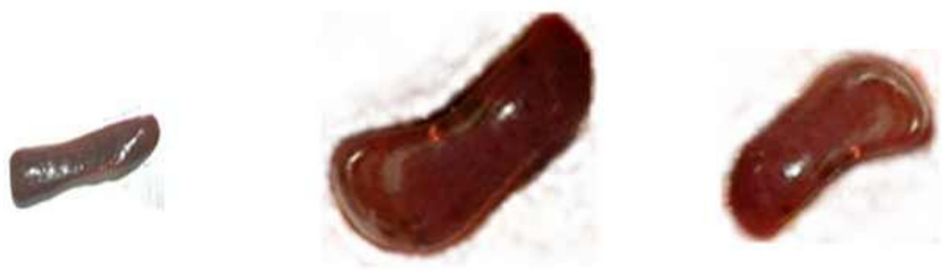

B

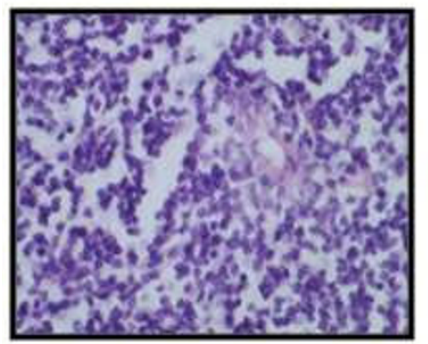

Control

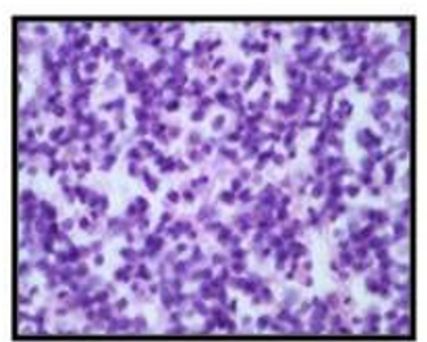

F1 (tg)

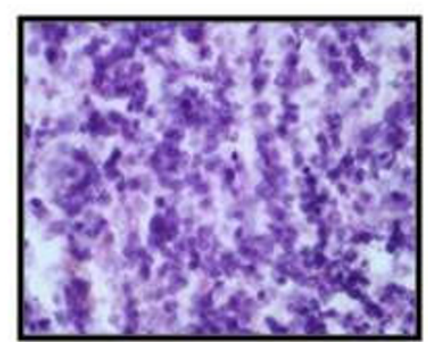

F2 (tg)

Figure 3 Morphological changes and histological analysis of the spleen in splenomegaly. A. Distinct splenomegaly-related changes were observed in the transgenic mice. The spleen weights of the transgenic mice were remarkably higher (21-fold increase in F1 and 11 -fold increase in F2) than those of the control mice. B. Histological analysis of the spleen of the transgenic and control mice. Paraffin sections were stained with hematoxylin \& eosin (original magnification, $\times 400$ ). 


\begin{tabular}{|c|c|c|}
\hline \multicolumn{2}{|c|}{ Category } & \# of DEGs \\
\hline \multirow{2}{*}{ F1(tg) vs CON. } & UP & 764 \\
\hline & DOWN & 849 \\
\hline \multirow{2}{*}{ F2 (tg) vs CON. } & $\mathbf{U P}$ & 1155 \\
\hline & DOWN & 1264 \\
\hline \multirow{2}{*}{ F2(tg) vs F1(tg) } & $\mathbf{U P}$ & 20 \\
\hline & DOWN & 243 \\
\hline \multicolumn{3}{|c|}{ Total $($ UP+DOWN) : 2672} \\
\hline
\end{tabular}

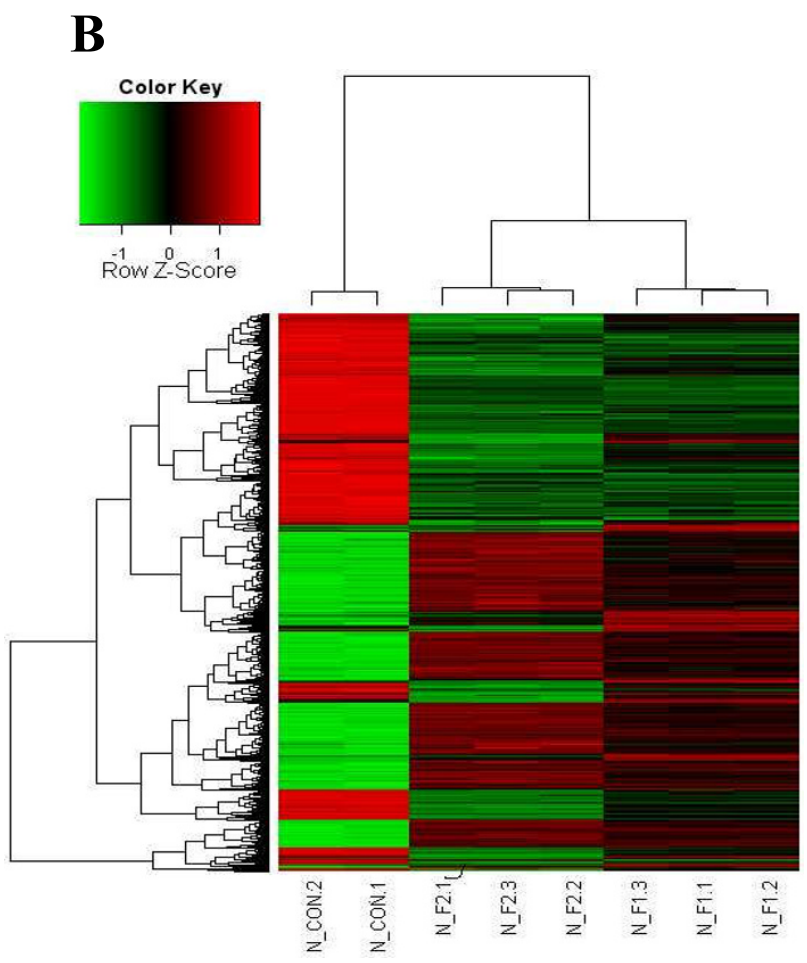

Figure 4 Microarray image and data analysis. A. Statistical significance of each correlation coefficient was determined using a corrected (Benjamini \& Hochberg algorithm) $P$ value $(P<0.05)$. B. Heat map and cluster analysis of gene expression measurements normalized to a single array showing genes in rows and samples in columns. Columns 1, 2: control mice; columns 3, 4, 5: F2 (tg); columns 6, 7, 8: F1 (tg); Con, control; tg, transgenic.

processes revealed that the responsive genes were related to 29 biological processes, including signal transduction (16\%), nucleoside, nucleotide, and nucleic acid metabolism (12\%), immunity and defense (11\%), protein metabolism and modification (9\%), developmental processes $(7 \%)$, cell cycle $(6 \%)$, and cell structure and motility $(5 \%)$ (Figure $5 \mathrm{~A})$. In the categorization based on molecular function, the genes were classified into 27 categories, as shown in Figure 5B. The most over-represented $\mathrm{GO}$ categories were concerned with nucleic acid binding (14\%), receptors (9\%), transcription factors (8\%), select regulatory molecules (7\%), and signaling molecules $(5 \%)$. Additionally, we functionally categorized transcripts that showed a $>5.0$-fold increase in expression (data not shown). In this categorization, we obtained 12 categories for genes involved in biological processes, including signal transduction, immunity and defense, protein metabolism and modification, and nucleoside, nucleotide, and nucleic acid metabolism, and 13 categories for genes involved in molecular functions, including cytoskeletal proteins, defense/immunity proteins, and hydrolases. A total of 25 genes were classified, and we represented a range of changes observed in microarray studies (5.12- to 44.57-fold changes for upregulated genes; data not shown). A partial list of the transcripts that showed a $<-5.0$-fold change (decrease) in expression was also obtained (data not shown). Twentyfour of the gene categories in this list were associated with biological processes such as immunity and defense (34\%), signal transduction (26\%), developmental processes $(8 \%)$, and protein metabolism and modification (5\%), and 21 categories of genes were associated with molecular functions such as defense/immunity proteins (33\%), receptors $(32 \%)$, signaling molecules $(14 \%)$, and kinases (12\%). In this categorization, a total of 153 genes were classified that represented a range of changes observed in microarray studies (-5.01- to -81.38-fold changes for repressed genes; data not shown).

\section{Independent microarray validation using RT-PCR and qRT-} PCR

Among all the cDNAs identified in the microarray study, we decided to narrow the search for candidate genes to 20 genes specific to the spleen (Table 3). These candidate genes were chosen according to the specific selection criterion of having a low or high impact on biological processes and molecular functions, e.g., genes associated with receptors, signal transduction, and immunity/defense. RT-PCR and qRT-PCR were conducted to validate the microarray results for the mRNA 

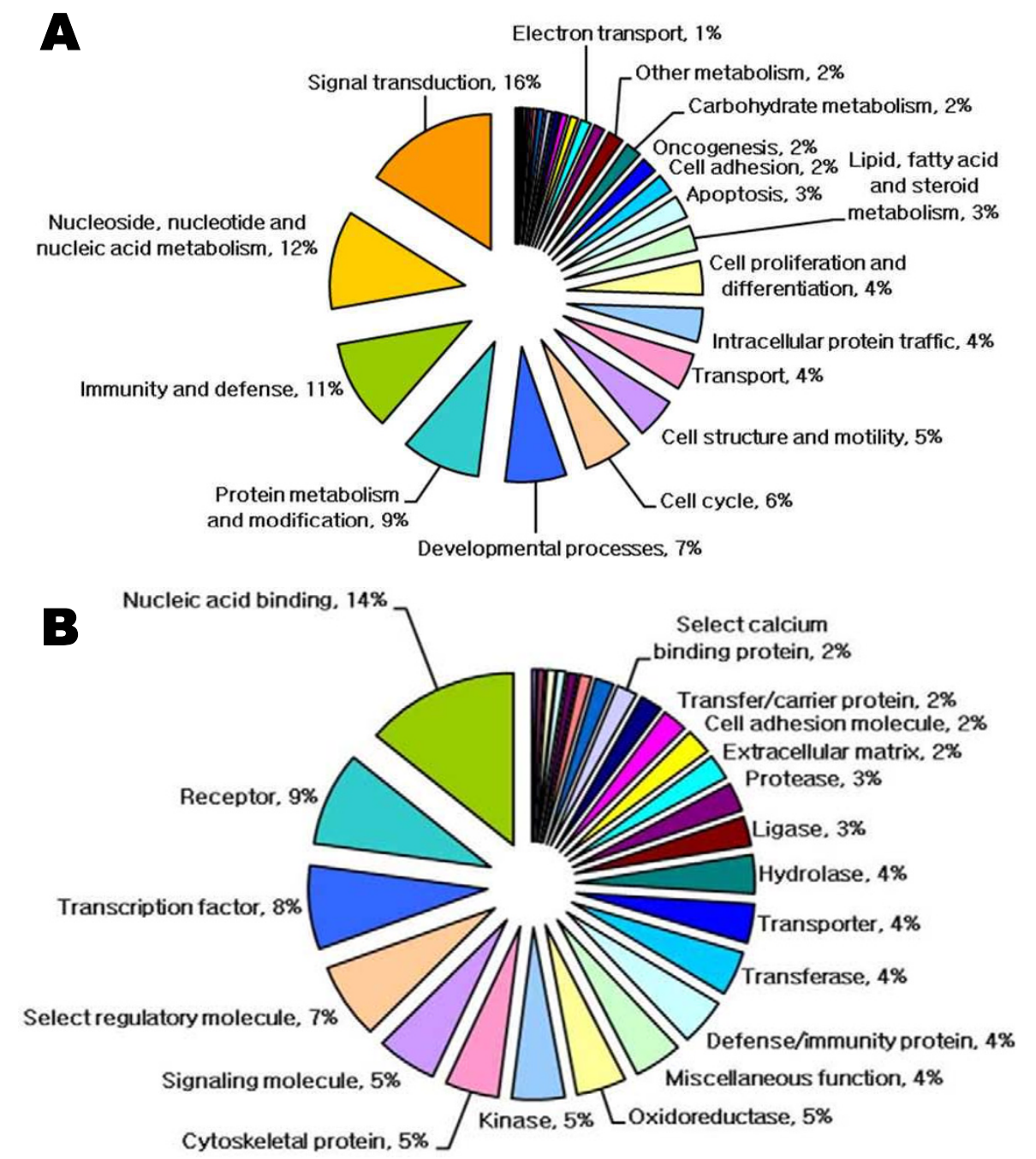

Figure 5 Functional categorization of the genes showing significant transcriptional differences in the transgenic and control mice. A total of 2,672 genes were categorized on the basis of Gene Ontology (GO) annotation, and the proportion of each category is displayed on the basis of biological process (A) and molecular function (B).

levels of the selected 20 clones (Figure 6). The 20 genes showed significantly different expression. The transcript abundance patterns of the control and tg mice were compared with the microarray data. All the genes analyzed showed the same expression patterns by qRT-PCR as noted in the microarray data. Figure 6 shows the expression levels of the 20 genes (10 genes showing upregulation and 10 showing downregulation). For example, in comparison with its expression in wt mice, the Pf4 gene (NM_019932) showed 5.4- to 5.8-fold upregulation in tg mice by qRT-PCR, consistent with the 3.8- to 4.9-fold higher expression seen in tg mice in the microarray data. Furthermore, the expression profiles of 10 genes, including $H 2-D M b 2$ (NM_010388), and 4 other genes with significant transcriptional changes, including [Cxcr5 (NM_007551), Fcrla
(NM_145141), Cfd (NM_013459), and Clec4g (NM_110691)], were analyzed in the spleens of the control and tg mice. As expected, all these genes were downregulated in tg mice. Noticeably, the expression level of the H2-DMb2 (NM_010388) gene was 50-100fold lower in tg mice than in wt mice.

\section{Discussion}

The dimer of 2 human EPO molecules linked by peptide linkers shows higher erythropoietic activity than the monomeric molecule, and this enhanced activity was observed both in vitro in primary human erythroid progenitors and in vivo in normal mice [7,9]. On the basis of these results, an expression vector producing $\mathrm{dHuEPO}$ protein was constructed to utilize the fusion system of 2 human EPO molecules linked by a peptide 
Table 3 Genes differing in their expression levels between control and tg (F1 or F2) spleen

\begin{tabular}{|c|c|c|c|c|}
\hline No. & $\begin{array}{c}\text { NCBI } \\
\text { Accession } \\
\text { Number }\end{array}$ & Gene & $\begin{array}{l}\text { F1/ } \\
\text { Con }\end{array}$ & $\begin{array}{l}\text { F2/ } \\
\text { Con }\end{array}$ \\
\hline \multicolumn{5}{|c|}{ Elevated in tg } \\
\hline 1 & NM_019932 & Platelet factor 4 & 4.98 & 3.86 \\
\hline 2 & NM_144559 & Fc receptor, IgG, low affinity IV & 10.46 & 2.04 \\
\hline 3 & NM_009921 & Cathelicidin antimicrobial peptide & 16.80 & 7.96 \\
\hline 4 & NM_017370 & Haptoglobin & 10.41 & 1.77 \\
\hline 5 & NM_015779 & Elastase, neutrophil expressed & 15.81 & 3.81 \\
\hline 6 & NM_144554 & Tribbles homolog 3 & 44.57 & 31.60 \\
\hline 7 & NM_175093 & Tribbles homolog 3 (Drosophila) & 8.93 & 6.82 \\
\hline 8 & NM_009114 & S100 calcium binding protein A9 & 7.72 & 4.95 \\
\hline 9 & NM_013738 & Pleckstrin 2 & 5.30 & 6.50 \\
\hline 10 & NM_008039 & Formyl peptide receptor 2 & 8.97 & 2.33 \\
\hline \multicolumn{5}{|c|}{ Reduced in tg } \\
\hline 11 & NM_010388 & $\begin{array}{l}\text { Histocompatibility 2, class II, locus } \\
\text { Mb2 }\end{array}$ & -32.53 & -19.50 \\
\hline 12 & NM_007551 & $\begin{array}{l}\text { Chemochine (C-X-C motif) receptor } \\
5\end{array}$ & -25.45 & -14.77 \\
\hline 13 & NM_145141 & Fc receptor-like A & -22.73 & -15.10 \\
\hline 14 & NM_013459 & Complement factor D (adipsin) & -21.51 & -15.43 \\
\hline 15 & XM_110691 & $\begin{array}{l}\text { C-type lectin domain family } 4 \text {, } \\
\text { member } g\end{array}$ & -14.94 & -6.47 \\
\hline 16 & NM_009835 & Chemokine (C-C motif) receptor 6 & -41.86 & -17.43 \\
\hline 17 & NM_008339 & CD79B antigen & -23.98 & -20.22 \\
\hline 18 & NM_170702 & CD40 antigen & -11.54 & -10.61 \\
\hline 19 & NM_009852 & CD6 antigen & -11.11 & -16.07 \\
\hline 20 & NM_019923 & $\begin{array}{l}\text { Inositol 1,4,5-triphosphate receptor } \\
2\end{array}$ & -4.04 & -5.03 \\
\hline
\end{tabular}

Gene names correspond to their Unigene identification where possible, and otherwise their Affymetrix identifier. Genes are displayed from the greatest to least fold-change and the specified tg/control expression ratio is indicated

linker of 2 amino acids (Asp-Ile). Several medical proteins have been successfully produced using goat promoter systems. Using the goat $\beta$-casein promoter, therapeutic proteins have been expressed at high levels in the milk of tg mice [26]. We designed the dHuPEO gene by recombinant DNA-mediated fusion of EPO coding regions linked by the Asp-Ile peptide and analyzed the physiological characteristics of the dHuEPO transgenic mice. The dHuEPO tg mice exhibited splenomegaly and abnormal blood composition. The inserted $d H u E P O$ gene was detected in all mouse tissues tested. Most of the tg mice tended to show abnormal symptoms, e.g., short life span. We identified 2,672 candidate genes in the spleen by microarray analysis; more genes were downregulated than upregulated in tg mice showing splenomegaly.

We found that the spontaneous abortion rate was high in the tg mice. Twenty-nine recipients (56\%) successfully farrowed after dHuEPO tg embryo transfer. Song et al. [27] reported that lanosterol $14 \alpha$-demethylase (LDM) is selectively expressed in preimplantation embryos and the uterine subluminal stroma surrounding the implanting blastocyst on day 5 of pregnancy. A high level of LDM expression is also observed in the uterus deciduas on day 6-8 of pregnancy, indicating that LDM is closely related to mouse embryo implantation. Therefore, $\mathrm{dHuEPO}$ embryos maybe have perturbation in sterol biosynthesis and metabolism during the peri-implantation period, leading to a high rate of spontaneous abortion or death. We observed that tg males, including F1 and F2 individuals, had a short life span. Several groups have reported premature mortality in polycythemic mice [18,28-30]. In contrast, other groups did not observe shortened life span in a series of human EPO tg mouse lines with elevated mean HCTs ranging from $48 \%$ to $80 \%$ [31-33]. In the present study, the F1 and F2 tg mice tested had HCT values of $74 \%$ and $63 \%$, respectively. The HCT values of the tg mice were markedly higher than that of the controls (47\%). Madan et al. [34] suggested that different mouse strains may differ in their ability to tolerate the rheological and hemodynamic effects of increased blood viscosity due to an elevated HCT. Kim et al. [35] reported that the life span of hEPO tg mice may be affected, and these animals may die of microcytic anemia and acute leukemia. The tg females (F1/F2) experienced spontaneous abortion during mid-to-late pregnancy. Thus, we were unable to obtain dHuEPO protein in their milk. Toth et al. [36] reported that EPO-receptor (EPO-R) expression in the villous trophoblast of the abortion tissue in tg mice was significantly higher than the normal EPO-R levels in humans. Although there is no experimental evidence to support the direct cause of these abortions, it is possible that the expression of EPO- $\mathrm{R}$ is upregulated in the placenta of the abortion tissue. EPO levels in the amniotic fluid correlate well with the EPO levels in the cord plasma and are significantly higher in pregnancies complicated by hypertension than in normal pregnancies [37].

The ectopic expression of a transgene can be influenced by the site of integration, the absence of specific regulatory elements in the promoter, and the presence of negative regulatory elements $[38,39]$. Ectopic expression of the EPO gene has been shown to cause harmful effects on the survival, health, and growth of some tissues in tg mice $[35,40]$. In our study, tg mice expressed dHuEPO mRNA in a variety of tissues, including the heart, kidney, liver, lung, and spleen. Thus, it is possible that ectopic expression of $\mathrm{dHuEPO}$ caused multiple organ failure in tg mice. F1 and F2 tg mice showed splenomegaly, and the weight of the spleen increased by 21 and 11-fold, respectively. A previous study reported that enhanced erythropoiesis occurred in tg spleens, accompanied by an up to 5 -fold increase in weight [20]. In studies of inpatients with splenomegaly, hematological 


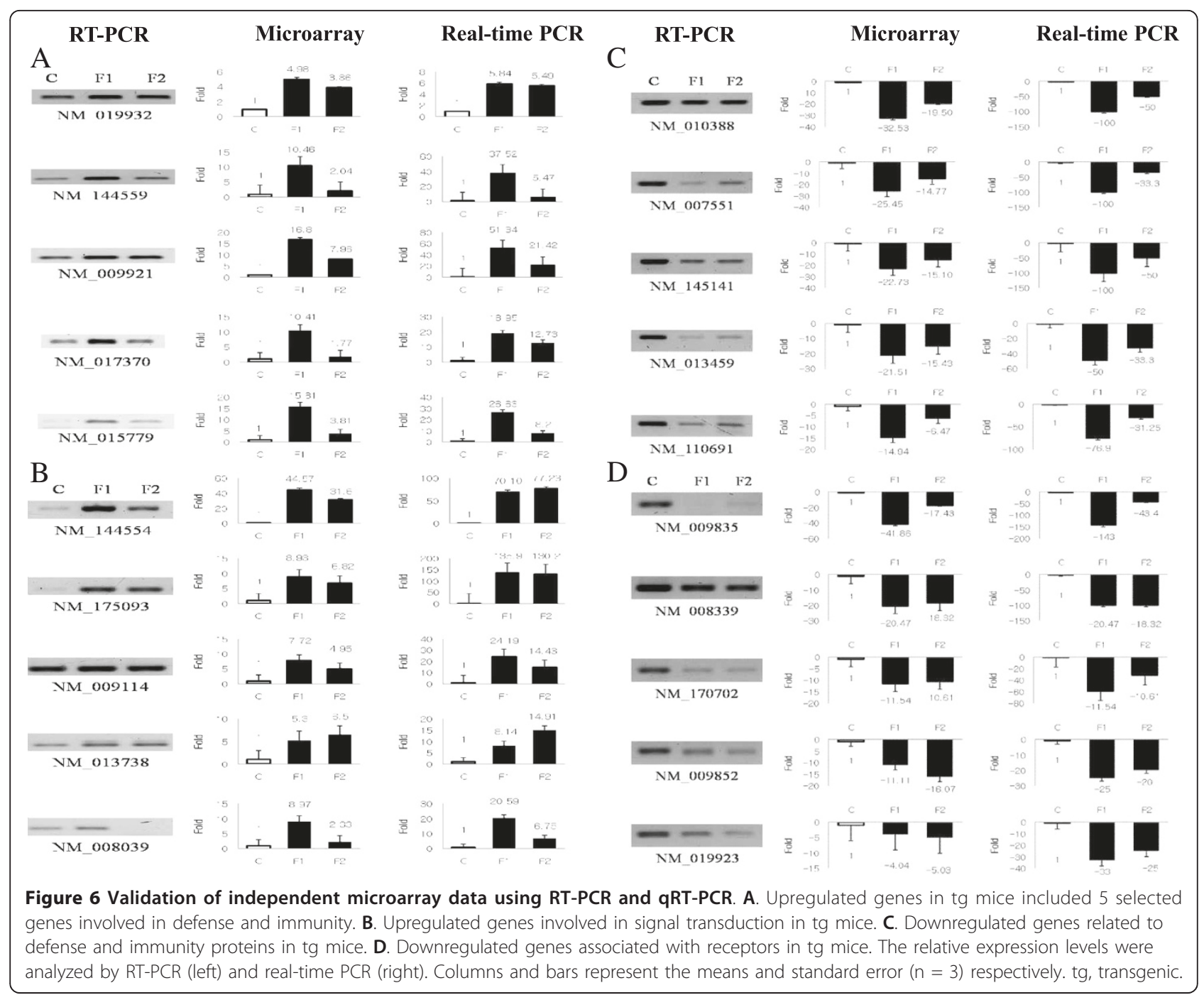

diseases were positively associated with lymphadenopathy, massive splenomegaly, and cytosis (erythrocytosis, leukocytosis, and thrombocytosis) [41,42]. O'Reilly et al. [43] reported that $84 \%$ of the cases with progressive splenic enlargement were associated with hematological disease, predominantly malignancy. In the present study, the RBC counts were higher in the tg mice than in the controls, which might have caused an increase in the spleen weight of the tg mice carrying the $\mathrm{dHuEPO}$ gene. The tg spleens showed a higher red pulp area than did wt spleens. Histological analysis revealed extramedullary erythropoiesis in the spleen, and erythropoietic activity was visualized using the monoclonal antibody ER-HR3 [20]. Our data indicated a similar incidence of massive splenic erythropoiesis in tg mice. Both extramedullary erythropoiesis and splenomegaly could cause classic complications in human patients suffering from polycythemia vera [44]. In the present study, we found that the HCT values in tg mice were higher than those in the controls (wt, $47 \%$ vs. tg F1, 74\% and tg F2, 63\%). Similar to these observations, the HCT values increased from 0.41 to 0.89 in tg mice. HCT levels of splenectomized tg mice were reduced by about $30 \%$ from 0.89 to 0.62 [20]. Most of the EPO tg mice showed severe nerve fiber degeneration of the sciatic nerve, a decreased number of neuromuscular junctions, and degeneration of skeletal muscle fibers. Thus, chronically increased EPO levels induced excessive erythrocytosis and led to multiple organ degeneration, thereby providing an explanation for the reduced life expectancy [19]. Erythrocyte aging of EPO tg mice was observed to be accelerated, which, together with an increased number and activity of macrophages, resulted in enhanced erythrocyte clearance [18]. These results indicate that extramedullary erythropoiesis can cause splenomegaly in tg mice.

A number of studies have employed microarray technology to characterize gene expression profiles [45-47]. Accordingly, this study was designed to provide data on 
the changes in the gene expression profile in the spleen of $\mathrm{dHuEPO}$ tg mice. Our results showed that a total of 2,672 genes were differentially expressed in the spleen of $\mathrm{tg}$ mice, in comparison to their expression in the controls. Furthermore, the expression of 153 of these genes ( $<5$-fold change, $P<0.05$ ) was repressed, and the expression of 25 genes $(>5$-fold change, $P<0.05$ ) was promoted. The tg spleens had more downregulated genes than the controls, including genes for defense/ immunity proteins and receptor-related genes; this suggests that the spleen is a major site for immunological elimination. Commonly used techniques for validation of microarray data include RT-PCR, qRT-PCR, northern blot, ribonuclease protection assay, and in situ hybridization or immunohistochemistry [48]. We used RT-PCR and qRT-PCR to validate our microarray data. Although the standard deviations in the expression levels of validated genes tended to be different, they matched the microarray patterns for the most part. These changes in gene expression profiles may provide a molecular framework to explain the complex differences in the splenic phenotypes of $\mathrm{dHuEPO}$ tg mice. Moreover, these results provide a global picture of gene expression differences in splenomegaly.

\section{Conclusions}

We generated $\mathrm{dHuEPO}$ tg mice using the goat $\beta$-casein promoter system, but this system had a negative effect on survival. Moreover, we were unable to obtain $\mathrm{dHuEPO}$ protein from the milk of these mice. Tg mice caused excessive erythrocytosis that led to abnormal blood composition, short lifespan, and abnormal splenomegaly. We have identified 2,672 genes associated with splenomegaly by microarray analysis in these mice. Thus, further studie is required to define these symptoms (excessive erythrocytosis, short lifespan and excessive splenomegaly) in dHuEPO tg mice.

\section{Acknowledgements}

The authors thank HH Seong (Institute of Animal Science) for helpful discussions and Mrs. YS Kang for technical assistance.

\section{Author details}

${ }^{1}$ Animal Biotechnology, Graduate School of Bio \& Information Technology, Institute of Genetic Engineering, Hankyong National University, Ansung 456749, Korea. ${ }^{2}$ Department of Food and Nutrition, Hoseo University, Asan 336795 , Korea.

\section{Authors' contributions}

SJY, PN, CWP, and TN performed the experiments. JJP, BWS, and MHK drafted the manuscript. SYH, JTY, and KSM designed supervised the experimental work, and revised the manuscript. All authors read and approved the final manuscript.

\section{Competing interests}

The authors declare that they have no competing interests.
Received: 22 October 2011 Accepted: 27 January 2012

Published: 27 January 2012

\section{References}

1. Stein RS, Abels RI, Krantz SB: Pharmacologic does of recombinant human erythropoietin in the treatment of myleodysplastic syndromes. Blood 1991, 78(7):1658-1663.

2. Henry DH, Beall GN, Benson CA, Carey J, Cone LA, Eron LJ, Fiala M, Fischl MA, Gabin SJ, Gottlieb MS: Recombinant human erythropoietin in the treatment of anemia associated with human immunodeficiency virus (HIV) infection and zidovudine therapy. Overview of four clinical trials. Ann Intern Med 1992, 117(9):739-748.

3. Buemi M, Aloisi C, Cavallaro E, Corica F, Floccari F, Grasso G, Lasco A, Pettinato G, Ruello A, Sturiale A, Frisina N: Recombinant human erythropoietin (rHuEPO): more than just the correction of uremic anemia. J Nephrol 2002, 15(2):97-103.

4. Ng T, Marx G, Littlewood T, Macdougall I: Recombinant erythropoietin in clinical practice. Postgrad Med J 2003, 79(933):367-376.

5. Macdougall IC, Eckardt KU: Novel strategies for stimulating erythropoiesis and potential new treatments for anaemia. Lancet 2006, 368(9539):947-953.

6. Bunn HF: New agents that stimulate erythropoiesis. Blood 2007, 109(3):868-873.

7. Dalle B, Henri A, Rouyer-Fessard P, Bettan M, Scherman D, Beuzard $Y$, Payen E: Dimeric erythropoietin fusion protein with enhanced erythropoietic activity in vitro and in vivo. Blood 2001, 97(12):3776-3782.

8. Qiu H, Belanger A, Yoon HWP, Bunn HF: Homodimerazation restores biological activity to an inactive erythropoietin mutant. J Biol Chem 1998, 273(18):11173-11176.

9. Syktowski AJ, Lunn ED, Risinger MA, Davis KL: An erythropoietin fusion protein comprised of identical repeating domains exhibits enhanced biological properties. J Biol Chem 1999, 274(35):24773-24778.

10. Macdougall IC, Gray SJ, Elston O, Breen C, Jenkins B, Brown J, Egrie J: Pharmacokinetics of novel erythropoiesis stimulating protein compared with epoetin alfa in dialysis patients. J Am Soc Nephrol 1999, 10(11):2392-2395.

11. Fares F, Ganem S, Hajouj T, Agai E: Development of a long-acting erythropoietin by fusing the carboxyl-terminal peptide of human chorionic gonadotropin $\beta$-subunit to the coding sequence of human erythropoietin. Endocrinology 2007, 148(10):5081-5087.

12. Park JJ, Lee HG, Nam IS, Park HJ, Kim MS, Chung YH, Naidansuren PJ, Kang HY, Lee PY, Park JG, Seong HH, Chang WK, Min KS: Biological activity of recombinant human erythropoietin (EPO) in vivo and in vitro. Reprod Dev Biol 2005, 29(2):69-79.

13. Naidansuren PJ, Min KS: Development and characterization of hyperglycosylated recombinant human erythropoietin (HGEPO). Reprod Dev Biol 2009, 33(2):77-83.

14. Naidansuren PJ, Min KS: Biological activity of human dimeric hyperglycosylated erythropoietin (dHGEPO) fusion proteins. Reprod Dev Biol 2010, 34(4):289-297.

15. Houdebine LM: Transgenic animal bioreactors. Transgenic Res 2000, 9(45):305-312.

16. Houdebine LM: Antibody manufacture in transgenic animals and comparisons with other systems. Curr Opin Biotechnol 2002, 13(6):625-629.

17. Archibald AL, McClenaghan M, Hornsey V, Simons JP, Clark AJ: High-level expression of biologically active human 1-antitrypsin in the milk of transgenic mice. Proc Natl Acad Sci USA 1990, 87(13):5178-5182.

18. Bogdanova A, Mihov D, Lutz H, Saam B, Gassmann M, Vogel J: Enhanced erythro-phagocytosis in polycythemic mice overexpressing erythropoietin. Blood 2009, 110(2):762-769.

19. Heinicke K, Baun O, Ogunshola OO, Vogel J, Stallmach T, Wolfer DP, Keller S, Weber K, Wagner PD, Gassmann M, Djonov V: Excessive erythrocytosis in adult mice overexpressing erythropoietin leads to hepatic, renal, neuronal, and muscular degeneration. Am J Physiol Regul Integr Comp Physiol 2006, 291:R947-R956.

20. Vogel J, Kiessling I, Heinicke K, Stallmach T, Ossent P, Vogel O, Aulmann M, Frietsch T, Schmid-Schonbein H, Kuschinsky W, Gassmann M: Transgenic mice overexpressing erythropoietin adapt to excessive erythrocytosis by regulating blood viscosity. Blood 2003, 102(6):2278-2284. 
21. Park JK, Lee YK, Lee P, Chung HJ, Kim S, Lee HG, Seo MK, Han JH, Park CG, Kim HT, Kim YK, Min KS, Kim JH, Lee HT, Chang WK: Recombinant human erythropoietin produced in milk of transgenic pigs. J Biotechnol 2006, 122(3):362-371.

22. Min KS, Hiyama T, Seong HH, Hattori N, Tanaka S, Shiota K: Biological activities of tethered equine chorionic gonadotropin (eCG) and its deglycosylated mutants. J Reprod Dev 2004, 50(3):297-304.

23. Hogan B: Molecular biology, enhancers, chromosome position effects and transgenic mice. Nature 1983, 306(5941):313-314.

24. Panther database. [http://www.pantherdb.org].

25. Primer3 software. [http://www.bioneer.co.kr/tools/].

26. Ziomek CA: Commercialization of proteins produced in the mammary gland. Theriogenology 1998, 49(1):139-144.

27. Song X, Tai P, Yan J, Xu B, Chen X, Ouyang H, Zhang M, Xia G: Expression of regulation of lanosterol 14a-demethylase in mouse embryo and uterine during the peri-implantation period. Reprod Fertil Dev 2008, 20(8):964-972.

28. Semenza GL, Traystman MD, Gearhart JD, Antonarakis SE: Polycythemia in transgenic mice expressing the human erythropoietin gene. Proc Natl Acad Sci USA 1989, 86(7):2301-2305.

29. Villeval $J$, Metcalf $D$, Johnson GR: Fatal polycythemia induced in mice by dysregulated erythropoietin production by hematopoietic cells. Leukemia 1992, 6(2):107-115

30. Prchal JT, Semenza GL, Sokol LP: Familial polycythemia. Science 1995, 268(5219):1831-1832.

31. Madan A, Lin C, Hatch SL, Curtin PT: Regulated basal, inducible, and tissue-specific human erythropoietin gene expression in transgenic mice requires multiple cis DNA sequences. Blood 1995, 85(10):2735-2741.

32. Kochling J, Curtin PT, Madan A: Regulation of human erythropoietin gene induction by upstream flanking sequences in transgenic mice. $\mathrm{Br} J$ Haematol 1998, 103(4):960-968.

33. Wagner KF, Katschinski DM, Hasegawa J, Schumacher D, Meller B, Gembruch U, Schramm U, Jelkmann W, Gassmann M, Fandrey J: Chronic inborn erythrocytosis leads to cardiac dysfunction and premature death in mice overexpressing erythropoietin. Blood 2001, 97(2):536-542.

34. Madan A, Lin C, Wang Z, Curtin PT: Autocrine stimulation by erythropoietin in transgenic mice results in erythroid proliferation without neoplastic transformation. Blood Cells Mol Dis 2003, 30(1):82-89.

35. Kim MO, Kim SH, Shin MJ, Lee DB, Kim TW, Kim KS, Ha JH, Lee S, Park YB, Kim SJ, Ryoo ZY: Human erythropoietin induces lung failure and erythrocytosis in transgenic mice. Mol Cells 2007, 23(1):17-22.

36. Toth B, Fischl A, Scholz C, Kunze S, Friese K, Jeschke U: Erythropoietin and erythropoietin receptor expression in normal and disturbed pregnancy. Eur J Obstet Gynecol Reprod Biol 2008, 140(2):192-200.

37. Teramo KA, Hiilesmaa VK, Schwartz R, Clemons GK, Widness JA: Amniotic fluid and cord plasma erythropoietin levels in pregnancies complicated by preeclampsia, pregnancy-induced hypertension and chronic hypertension. J Perinat Med 2004, 32(3):240-247.

38. Semenza GL, Dureza RD, Traystman MD, Gearhart JD, Antonarakis SE: Human erythropoietin gene expression in transgenic mice: multiple transcription initiation sites and cis-acting regulatory elements. Mol Cell Biol 1990, 10(3):930-988.

39. Barash I, Faerman A, Ratovitsky T, Puzis R, Nathan M, Hurwitz DR, Shani M: Ectopic expression of $\beta$-lactoglobulin/human serum albumin fusion genes in transgenic mice: hormonal regulation and in situ localization. Transgenic Res 1994, 3(3):141-151.

40. Massoud M, Atta J, Thepot D, Pointu H, Stinnakre MG, Theron MC, Lopez C, Houdebine LM: The deleterious effects of human erythropoietin gene driven by the rabbit whey acidic protein gene promoter in transgenic rabbits. Reprod Nutr Dev 1996, 36(5):555-563.

41. Pozo AL, Godfrey EM, Bowles KM: Splenomegaly: investigation, diagnosis and management. Blood Reviews 2009, 23(3):105-111.

42. Swaroop J, O'Reilly RA: Splenomegaly at a university hospital compared to a nearby county hospital in 317 patients. Acta Haematol 1999, 102(2):83-88.

43. O'Reilly RA: Splenomegaly in 2505 patients at a large university medical centre from 1913 to 1995.1963 to 1995: 449 patients. West J Med 1998, 169(2):88-97.

44. Pearson TC: Evaluation of diagnostic criteria in polycythemia vera. Semin Hematol 2001, 38(1):21-24
45. Hashizume K: Analysis of uteroplacental-specific molecules and their functions during implantation and placentation in the bovine. J Reprod Dev 2007, 53(1):1-11.

46. Kao LC, Tulac S, Lobo S, Imani B, Yang JP, Germeyer A, Osteen K, Taylor RN, Lessey BA, Giudice LC: Global gene profiling in human endometrium during the window of implantation. Endocrinology 2002, 143(6):2119-2138.

47. Wada K, Howard JT, McConnell P, Whitney O, Lints T, Rivas MV, Horita H, Patterson MA, White SA, Scharff C, Haesler S, Zhao S, Sakaguchi H, Hagiwara M, Shiraki T, Hirozane-Kishikawa T, Skene P, Hayashizaki Y, Carninci $P$, Jarvis ED: A molecular neuroethological approach for identifying and characterization a cascade of behaviorally regulated genes. Proc Natl Acad Sci USA 2006, 103(41):15212-15217.

48. Chuaqui RF, Bonner RF, Best CJ, Gillespie JW, Flaig MJ, Hewitt SM, Phillips JL, Krizman DB, Tangrea MA, Ahram M, Linehan WM, Knezevic V, Emmert-Buck MR: Postanalysis follow-up and validation of microarray experiments. Nature Genet 2002, 32:509-514.

doi:10.1186/1477-7827-10-6

Cite this article as: Yun et al:: Aberrant phenotypes of transgenic mice expressing dimeric human erythropoietin. Reproductive Biology and Endocrinology 2012 10:6.

\section{Submit your next manuscript to BioMed Central and take full advantage of:}

- Convenient online submission

- Thorough peer review

- No space constraints or color figure charges

- Immediate publication on acceptance

- Inclusion in PubMed, CAS, Scopus and Google Scholar

- Research which is freely available for redistribution 